\title{
Editorial Note
}

To commemorate the 25th anniversary of the Journal of Southeast Asian Studies the Editors have invited scholars representing various disciplines to take part in a sort of intellectual stock-taking by preparing articles assessing the state of academic knowledge on the region. The manuscripts will appear in this Special Issue, and in the September 1995 issue of the Journal. As might be expected the contributors differ widely in their approaches, but taken collectively they share a common view that the field is undergoing a re-assessment of concepts and approaches that should generate fruitful research and writing during the coming years.

On behalf of the Editorial Board, we should like to express our deep appreciation to the scholars who invested their time and intellectual energies in the preparation of articles for this Special Issue. We hope that our readers will share our own feeling that the result is a publication that will be read and re-read, and make its own contribution to the shaping of Southeast Asian Studies in the future. We should also like to take this opportunity to thank all those who have submitted articles and book reviews to the Journal over the past 25 years, and to the individuals and institutions whose subscriptions have covered the Journal's expenses. 